\title{
La recepción de Anna de Noailles en España: imágenes, impresiones y críticas con ocasión de su muerte
}

\author{
Francisco LAFARGA \\ Universitat de Barcelona \\ lafarga@ub.edu \\ https://orcid.org/0000-0003-0847-5011
}

\section{Resumen}

La personalidad y la obra de Anna de Noailles tuvieron cierta presencia en la edición española desde inicios de siglo hasta su muerte. En el ámbito de la prensa, se hallan numerosos comentarios, desde gacetillas meramente periodísticas hasta artículos y ensayos de corte literario. En este trabajo se tomarán en consideración los publicados en ocasión de su fallecimiento, sobre todo durante el mes de mayo de 1933, insistiendo en la imagen que proyectan de la autora y de su obra.

Palabras clave: Literatura femenina, Poesía, Prensa, Traducción

\section{Résumé}

La personnalité et l'œuvre d'Anna de Noailles ont eu une certaine présence dans l'édition espagnole depuis le début du siècle jusqu'au moment du décès de l'auteure. Dans le domaine de la presse il existe de nombreux commentaires, qui vont des bulletins de presse jusqu'à des articles ou des essais littéraires. Dans ce travail seront pris en considération les textes publiés à l'occasion du décès d'Anna de Noailles, parus notamment au cours du mois de mai 1933, en insistant sur l'image de l'auteure et de son œuvre qu'ils ont projetée.

Mots clé : Littérature féminine, Poésie, Presse, Traduction

\begin{abstract}
The personality and work of Anna de Noailles had a certain presence in the Spanish edition from the beginning of the XXth century until her death. In the field of the press, there are numerous comments, from merely press releases to articles and literary essays. In this work, those published on the occasion of her death, especially during the month of May 1933, will be taken into consideration, insisting on the image they project of the author and her work.
\end{abstract}

Keywords: Women Literature, Poetry, Press, Translation

* Artículo recibido el 17/06/2021, aceptado el 3/09/2021. 
Et la plus morte mort est d'avoir survécu (L'Honneur de souffrir, XIII)

Anna de Brancovan, condesa Mathieu de Noailles (1877-1933), fue uno de los personajes más relevantes de la escena literaria y social del primer tercio del siglo $\mathrm{XX}^{1}$. Aunque algún maldiciente afirmó que solo tenía de francesa el apellido de su marido, lo cierto es que esta greco-rumana de origen se sintió, desde su nacimiento parisiense, profundamente francesa y alcanzó un gran dominio de la lengua literaria. Su salón fue lugar de encuentro de numerosos literatos y artistas de la época, con algunos de los cuales tuvo especial relación, de signo variado (Maurice Barrès, Marcel Proust). Su constante asistencia a los actos sociales del grand monde no impidió su activa participación en distintas iniciativas en defensa de las libertades. Por otra parte, su nombre estuvo asociado al debate sobre la presencia de la mujer en la Académie française, que vetó una y otra vez el ingreso de escritoras; llegó a ser académica, aunque en Bélgica (Académie royale de langue et littérature françaises) ${ }^{2}$. Fundó, con otras escritoras, el premio Femina, y presidió el primer jurado del mismo (1904), que se reunió en su propia casa ${ }^{3}$.

La presencia de Anna de Noailles en España, según se desprende del análisis de la prensa del primer tercio del siglo XIX, fue sostenida y variada, pues sus actividades literarias, mundanas y sociales dieron pie a múltiples noticias y comentarios. Contribuyeron asimismo a aumentar la presencia unos anunciados viajes a Madrid y a Barcelona, que nunca se realizaron, y el retrato que hizo de ella Ignacio Zuloaga en $1913^{4}$.

\footnotetext{
${ }^{1}$ Este trabajo se ha realizado en el marco del proyecto de investigación Portal digital de Historia de la Traducción en España, PGC2018-095447-B-I00 (MCIU/AEI/FEDER, UE).

${ }^{2}$ A su muerte, su sillón (el 33) fue ocupado por otra mujer, Colette, quien dedicó a su amiga un sentido discurso; a Colette le siguió, en el mismo sillón, otro amigo de Anna de Noailles, Jean Cocteau.

${ }^{3}$ La bibliografía crítica sobre Anna de Noailles se inició ya en vida de la autora, y ha experimentado cierto auge en los últimos años. Tras los primeros estudios, debidos a G.-A. Masson (1922), R. Benjamin (1928) y J. Larnac (1931), mientras que críticos como L. Blum (1906) o Ch. Du Bos (1922) le dedicaron su atención, se produjo un largo periodo de olvido, en el que solo figura el libro de su amiga la duquesa de La Rochefoucauld (1956). El interés de la crítica renace en los años 1980 con las biografías de Cl. Mignot-Ogliastri (1986) y F. Broche (1989), a las que hay que añadir la reciente de F. Martinez (2018). También se constata una recuperación de su obra con varias reediciones, entre las que destaca la de su poesía completa (Noailles, 2013), al mismo tiempo que han aparecido varios estudios de envergadura gracias a C. Perry (2003), R. M. Verona (2011) y M.-L. Allard (2013). Conviene asimismo mencionar dos sitios en la red: la página Anna de Noailles, creada por Catherine Perry en 2009 (http://www.annadenoailles.org) y un blog, de autor desconocido, activo entre 2010 y 2016, con casi ochocientos archivos (http://comtessedenoailles.blogspot.com). En ámbito español, tras el artículo de Ortega y Gasset (1923) conviene mencionar el librito de M. Barbeito (1962) y el estudio de A. Piquer (1996), además de las páginas que le dedica C. Pujante (2014).

${ }^{4}$ La obra, que se encuentra en el Museo de Bellas Artes de Bilbao, produjo la reacción literaria de Rafael Sánchez Mazas con sus «Siete sonetos ante el retrato de la condesa de Noailles», publicados en 1917 en la revista Hermes ( $n^{\circ}$ 8, 521-522). Véase, para la relación entre Zuloaga y su modelo, Rementería (2001).
} 
Obviamente, estos motivos hicieron que su presencia en España, o el conocimiento que de ella podía tener el público lector español, fuera superior al de sus contemporáneas Gyp, Séverine, Rachilde, Myriam Harry, Marcelle Tinayre, Lucie Delarue-Mardrus o Gérard d'Houville. Tal vez Colette fue la única que suscitó parecido interés.

El estudio de la recepción de Anna de Noailles, como la de todo autor, se apoya en primer lugar en su presencia en el mundo de la edición. Las traducciones (véase Lafarga, 2020) ofrecen una continuada presencia en lengua española, gracias a una larga historia que se inicia en 1908 y llega hasta la actualidad, aunque es justo señalar el carácter fragmentario de dicha presencia, con publicaciones dispersas y en raras ocasiones con traducción de la obra completa, ya sea poemarios, ya obras en prosa. Al mismo tiempo, se aprecia la recuperación de la autora en los últimos años en el ámbito de la traducción, en consonancia con la nueva presencia de su obra en el mercado editorial francés. Conviene añadir que las traducciones no reflejan la riqueza y la variedad de su escritura: se ha privilegiado la poesía, que fue lo más alabado de su producción en vida, aunque han quedado en el olvido (también en Francia) la mayor parte de sus prosas, fundamentalmente poéticas.

Pero también es ilustrativo y necesario, aunque no siempre posible, dilucidar la recepción de la que un autor o una obra ha sido objeto. Y uno de los ámbitos (junto a la publicidad, la crítica literaria) es el impacto en los medios de comunicación, que para la época de este estudio es la prensa escrita.

Tras llevar a cabo el oportuno rastreo en las publicaciones periódicas del primer tercio del siglo XX, facilitado por la progresiva digitalización de los fondos hemerográficos ${ }^{5}$, he podido reunir un conjunto de 64 artículos con contenido literario, no meramente informativo. El número se duplica si se tienen en cuenta los artículos en los que Anna de Noailles es meramente citada, junto a otras escritoras, así como las gacetillas o noticias breves relativas a su vida pública, sus actividades sociales e incluso su compromiso político.

El acontecimiento de la vida de Anna de Noailles que más llamó la atención o, por lo menos, que suscitó mayor número de artículos de prensa fue, paradójicamente - o tal vez no tanto- su propia muerte. El que había sido motivo recurrente y obsesivo en sus últimos poemarios le proporcionó el último de sus triunfos personales y literarios: el tributo emocionado y numeroso de escritores, críticos y periodistas. Este hecho, que aporta cierta coherencia al discurso crítico de la prensa, ha aconsejado limitar en este estudio el corpus de textos a los vinculados

\footnotetext{
${ }^{5}$ La mayoría de las publicaciones que contienen datos útiles para este trabajo se encuentran en la Hemeroteca Digital de la Biblioteca Nacional de España (http://www.bne.es/es/Catalogos/HemerotecaDigital); de modo complementario, ha resultado provechosa la consulta de la Biblioteca Virtual de Prensa Histórica del Ministerio de Cultura y Deporte (https://prensahistorica.mcu.es/es/inicio/inicio.do). Para la prensa catalana he consultado ARCA (Arxiu de Revistes Catalanes Antigues) de la Biblioteca de Catalunya (https://arca.bnc.cat/arcabib_pro/ca/inicio/inicio.do), así como los propios archivos 0 hemerotecas de $A B C$ y Blanco $y$ Negro (https://www.abc.es/archivo/periodicos/) $\quad$ y $\quad$ de $\quad$ La $\quad$ Vanguardia
} (https://www.lavanguardia.com/hemeroteca). 
directamente con el fallecimiento de la autora, a los emanados, ciertamente, de un interés periodístico vinculado con la actualidad, pero que superan lo meramente anecdótico para alcanzar -en grado diverso, conviene adelantarlo- cierto nivel crítico y literario.

Los veinticuatro textos resultantes de esta limitación son de diversa índole y resultan, pese a su número, representativos de tendencias, modos de difusión y autoría. Antes de pasar a los contenidos, creo interesante abordar algunos aspectos externos.

En primer lugar, los autores de los artículos. Los veinticuatro textos son obra de veintitrés autores, que se reducen a veintiuno de nombre conocido, al aparecer uno de los artículos sin firma y otro estar suscrito por cierto M., cuya identidad no he podido averiguar. Por otra parte, seis autores son extranjeros, aunque alguno residió en España, particularmente en la época de publicación de su trabajo, como el venezolano Rufino Blanco Fombona ${ }^{6}$, el peruano José Díez Canseco ${ }^{7}$, el francés Aubin Rieu-Vernet ${ }^{8}$ y el italiano Giuseppe Torre Caprara ${ }^{9}$, que firmaba con varios seudónimos; a estos hay que añadir a los franceses Jean Cocteau ${ }^{10} \mathrm{y}$ Charles Malato ${ }^{11}$.

Por otra parte, debe señalarse la baja presencia de mujeres, pues solo son tres frente a dieciocho hombres (y eso sin contar a los dos autores sin nombre): se trata de Ernestina de Champourcin ${ }^{12}$, María Luz Morales ${ }^{13}$ y Matilde Ras ${ }^{14}$.

\footnotetext{
${ }^{6}$ Rufino Blanco Fombona (1874-1944), escritor y político venezolano, vivió fuera de su país muchos años y entre 1914 y 1936 residió en España, donde desarrolló gran actividad literaria (publicación de poemarios y novelas), periodística y política (véase Ruiza, Fernández y Tamaro, 2004).

${ }^{7}$ El peruano José Díez Canseco (1904-1949) ejerció el periodismo en su país, donde también se dedicó a la política, por lo cual tuvo que abandonarlo en varias ocasiones; al inicio de los años 1930 vivió en París y en Madrid, donde escribió para $A B C$.

${ }^{8}$ No he podido obtener información sobre Aubin Rieu-Vernet, salvo la mención de algunas publicaciones; ejerció el periodismo en Francia y en España, donde dirigió Cultura Integral y Femeni$n a$, siendo el único hombre del equipo de redacción.

${ }^{9}$ Giuseppe Torre Caprara fue un escritor antifascista italiano refugiado en Barcelona en los años 1930, donde colaboró en la prensa (La Publicitat y la revista Mirador) con artículos sobre la actualidad política y literaria. Usó los seudónimos Tiggis y Athos Novellis (véase Singla, 2006).

${ }^{10}$ Jean Cocteau (1889-1963) fue amigo de Anna de Noailles, con quien mantuvo correspondencia durante veinte años; escribió varios textos acerca de ella y le hizo un retrato.

${ }^{11}$ Charles Malato (1857-1938), de origen italiano, fue un notable anarquista francés, periodista y escritor. Amigo del libertario español F. Ferrer y Guardia, fue acusado de participar en un atentado contra Alfonso XIII, aunque resultó absuelto (véase Sin autor, s. a.).

12 Ernestina de Champourcin (1905-1999) fue una poeta muy vinculada a J. R. Jiménez y otros miembros de la generación del 27. Colaboró en la prensa madrileña de los años 20 y 30 y se dedicó también a la traducción (véase Fernández de Urtasun, s. a.)

${ }^{13}$ María Luz Morales (1890-1980), periodista, escritora y traductora, trabajó en varios periódicos, entre ellos El Sol y La Vanguardia, de la que fue directora durante la guerra civil (véase Marco López, s. a.).

${ }^{14}$ Matilde Ras (1881-1969) fue escritora, traductora y grafóloga. Publicó varias obras sobre este arte, así como relatos y ensayos; colaboró asiduamente en $A B C$ y Blanco Negro (véase M. Martínez, s. a.).
} 
En cuanto a las fechas de aparición de los artículos seleccionados, el punto de partida viene marcado por el fallecimiento de Anna de Noailles, que ocurrió el 30 de abril de 1933. No extraña, pues, que el mayor número de artículos (siete) aparecieran a lo largo de la primera semana de mayo; el ritmo descendió ligeramente durante la segunda semana (seis) y de modo más notable en la segunda quincena de mayo (otros seis). El número se completa con publicaciones tardías en junio, julio y agosto.

Un tercer aspecto interesante de subrayar es el tipo de publicación en el que aparecieron los artículos. De las dieciséis publicaciones contempladas, nueve son diarias y siete periódicas (semanales o mensuales). El espectro político o ideológico que se aprecia en los diarios (normalmente más marcados en este sentido que las revistas) va desde posiciones conservadoras de ABC, La Época, La Vanguardia o La Veu de Catalunya, pasando por progresistas y liberales como Heraldo de Madrid, El Sol y La Voz, hasta los francamente de izquierdas como La Libertad y Luz. En cuanto a las revistas, el arco va desde las conservadoras Contemporánea (asociada a la Orden de Predicadores) y Blanco Negro, hasta la anarquista y libertaria La Revista Blanca, o la abiertamente feminista Cultura Integral y Femenina. Entre unas y otras, aunque sin coloración ideológica definida, están las generalistas Mirador (en catalán) y Nuevo Mundo (gráfica), así como la literaria rupturista Cruz y Raya ${ }^{15}$.

Pasando a los contenidos, tal vez sea conveniente tomar en consideración por separado a los periódicos diarios y a las revistas, y por varias razones: el distinto distanciamiento temporal respecto del acontecimiento, la existencia de un público más específico (normalmente), un tono incluso diferente.

Los artículos aparecidos en la prensa diaria son los siguientes ${ }^{16}$ : de L. Araujo Costa en La Época, de Ceferino R. Avecilla en La Libertad, de R. Blanco Fombona en El Sol, de Manuel Bueno en ABC, de Miquel Capdevila en La Veu de Catalunya, de Lorenzo Carriba en Heraldo de Madrid, de Cristóbal de Castro en La Libertad, de Juan Chabás en Luz, de Ernestina de Champourcin en El Sol, de Jean Cocteau en Heraldo de Madrid, de José Díez Canseco en $A B C$, de Mauricio López Roberts, marqués de Torrehermosa, también en $A B C$, de cierto M. en $L a$ Veu de Catalunya, de María Luz Morales en La Vanguardia, de José María Pemán en $A B C$ y uno sin firma en $L a$ Voz.

La respuesta de la prensa diaria fue bastante rápida, habida cuenta de la sucesión de dos días festivos (el 1. ${ }^{\circ}$ de Mayo, Fiesta del Trabajo, y el Dos de Mayo, festivo nacional durante la Segunda República). Y si el primer artículo publicado, el 2 de mayo en $L a V o z$, que va sin firma, podría juzgarse como un texto de la redacción elaborado con urgencia, ya el aparecido el día siguiente en La Época,

\footnotetext{
${ }^{15}$ Sobre la situación de la prensa en el primer tercio del siglo XX pueden consultarse el estudio ya clásico de Seoane (1996), así como el más reciente de Pizarroso (2010); para la prensa catalana sigue siendo válida la historia de Torrent y Tasis (1966). También son útiles las descripciones de las publicaciones en el lugar correspondiente a cada una de ellas en la mencionada Hemeroteca Digital de la BNE.

${ }^{16}$ Véase en apéndice la referencia completa de cada uno de ellos.
} 
obra de Luis Araujo Costa ${ }^{17}$, se sitúa en la línea del ensayo, que va a predominar en los textos seleccionados.

Llama la atención la variedad de títulos dados a los artículos, desde el más periodístico «La condesa de Noailles ha muerto» de $L a V o z$, hasta los más creativos «El verso ignorado de la condesa de Noailles» de Ceferino R. Avecilla ${ }^{18}$, «La musa aristocrática» de Manuel Bueno ${ }^{19} \mathrm{o}$ «La hilandera lírica» de M. ${ }^{\mathrm{a}}$ Luz Morales. Es notable, por lo críptico y -en la mente del autor- unívoco, el título «Muerte de la poetisa» puesto a su artículo por Mauricio López Roberts ${ }^{20}$. Cabe decir que casi todos los artículos son altamente elogiosos. Está la excepción (parcial) del de Avecilla, que arranca con «Ya se han disuelto todas las exaltaciones que despertó la muerte de la señora condesa de Noailles. Puedo ya declarar, sin menoscabo de tal exaltación, que yo no sentí nunca la menor simpatía por aquella buena señora»; aunque a renglón seguido señala que, al enterarse de la ayuda prestada por la escritora a varias prostitutas, había corregido tal impresión, afirmando que fue «ejemplo de condesas [y superior a] todas las mujeres que creen tener un blasón en el ombligo y [a] todos los poetas que se figuran que su frente es la jaula de un pájaro azul».

Por otra parte, se hallan en estos artículos testimonios de algunos de sus redactores que conocieron personalmente a Anna de Noailles. Tal es el caso de Manuel Bueno durante su estancia en París, en 1924 o 1925, cuando su belleza empezaba a declinar, aunque conservaba la fascinación que siempre la acompañó, y que, según el escritor, podía apreciarse sobre todo a través de la palabra: «Pero apenas despegaba los labios aquella mujer, toda su persona inundábase de una luz sobrenatural. Era el desquite victorioso que toma siempre el espíritu de la materia. ¡Qué deliciosa conversación! ¡Qué finura de ingenio y qué prodigalidad graciosa!» (Bueno, 1933: 23).

También la conoció personalmente M. López Roberts en 1931, que da de ella un retrato físico acompañado de su característica más notable, el poder de la palabra, el dominio de la comunicación:

Era una mujer menuda, grácil, de aspecto gracioso y ligero, semejante al de un pájaro inquieto y siempre pronto a volar, Sus inmensos ojos orientales, negros, profundísimos, de un admirable fuego centelleante, casi devoraban el resto del ros-

\footnotetext{
${ }^{17}$ Luis Araujo Costa (1885-1956), escritor y periodista, es autor de varias obras de corte histórico y fue colaborador de varios periódicos, entre ellos La Época y $A B C$ (véase Cuenca Toribio, s. a.).

${ }^{18}$ Ceferino R. Avecilla (1880?-1956), en realidad Rodríguez Alonso de Avecilla, fue dramaturgo y periodista. Trabajó en periódicos como ABC, Blanco y Negro, La Libertad o La Tribuna. También se dedicó al mundo del fútbol como directivo (véase Martínez Patón, s. a.).

${ }^{19}$ Manuel Bueno Bengoechea (1874-1936), escritor y periodista, fundó y dirigió varios periódicos de corta vida, y colaboró en otros muchos, en particular en $A B C$ y Blanco y Negro; por otra parte, publicó novelas, piezas teatrales y ensayos (véase Biblioteca Nacional de España, s. a.).

${ }^{20}$ El diplomático y escritor Mauricio López Roberts (1873-1940), marqués de Torrehermosa, publicó varias novelas y colaboró en distintos periódicos y revistas (La Lectura, Blanco y Negro, $A B C$ ) con artículos sobre literatura y arte.
} 
tro, donde la nariz, fina y aguileña, parecía ser como una arista pronta a desaparecer ante el incendio de las maravillosas pupilas, aterciopeladas, y la boca, riente y melancólica, era estrecho cauce para el torrente sin fin de las palabras que fluían con abundancia y facilidad portentosas, llenas siempre de un calor comunicativo que hacía aceptables las más atrevidas paradojas, revestidas de un espléndido ropaje retórico, espontáneo, fresco, nuevo, evocador (López Roberts, 1933: $3)$.

Obviamente, quien mejor la conoció fue su amigo Jean Cocteau, de quien el Heraldo de Madrid publicó traducido el texto que había aparecido unos días antes en el monográfico que Les Nouvelles Littéraires dedicó a su más ilustre colaboradora (n. ${ }^{\circ} 551$, de 06/05/1933, p. 1). Retomando un tema poético y vital tan querido de la poetisa, la muerte, y apoyándose en conversaciones con ella al respecto, escribe un bello texto de tono intimista:

Madama de Noailles sabía muy bien que tenemos que permanecer mucho más tiempo muertos que vivos, y como el afán de la gloria es una de las formas más elevadas del instinto de conservación, ella vivía de manera a prepararse una larga vida de muerta (Cocteau, 1933: 13).

El artículo, que reproduce un autorretrato de Cocteau, lleva al final la mención «Comunicación de Julio Gómez de la Serna». Va precedido de una presentación, aparentemente del propio Gómez de la Serna, de quien supongo será también la traducción del texto.

Una vinculación personal, aunque meramente literaria, es la que evoca Ernestina de Champourcin en su artículo, rememorando cuánto debía -por lo menos en los inicios de sus actividades literarias- a la poesía de Anna:

La imagen de la condesa de Noailles surge en mi memoria, mezclada en absurda confusión, con el recuerdo de mis primeros entusiasmos literarios y de mis primeros poemas. Nuestro encuentro, ya lejano, en las páginas de una antología, dejó en mi espíritu una impresión vaga y luminosa, semejante a esas huellas de sol que persisten entre los párpados cerrados. Aquellos versos impetuosos, quizá algo enfáti$\cos$, en los que palpitaba una vida que yo ignoraba aún, me alucinaron totalmente. Durante mucho tiempo la poesía de esta mujer personificó para mí un mundo de sensaciones punzantes e inefables, de aromas exóticos: «les senteurs d'héliotrope et de vanille», que resumen la fragancia sensual de casi todos sus libros. Les forces éternelles fue el primer volumen suyo que cayó en mis manos. Tras los recuerdos de guerra, que componen una parte del tomo, encontré fácilmente la voz auténtica, el grito voluptuoso y pagano que más especialmente me atraían. [...] Anna de Noailles me enseñó a escuchar el silencio, «onduleux comme l'onde», y a sentir las vibraciones humanas del paisaje (de Champourcin, 1933: 2) 
Obviamente, más allá de los recuerdos personales, de los tributos y agradecimientos, están las observaciones precisas sobre la vida y, más interesantes, sobre la obra de Anna de Noailles.

Con todo, uno de los artículos, el anónimo de $L a V o z$, ya mencionado, que fue el primero en aparecer, resulta un texto de circunstancias, con una amplia nota biográfica, pocas alusiones a su obra y con el complemento del poema «Frente a España» (de Les Éblouissements), traducido por Fernando Fortún e incluido en la conocida antología La poesía francesa moderna de Enrique Díez-Canedo y el propio Fortún (Madrid, Renacimiento, 1913). Hay, con todo, un detalle que llama la atención, y es la inclusión de este comentario, muy de acuerdo con la línea editorial del periódico: «Todas las grandes causas y los oprimidos encontraron en esta dama desinteresada defensa, a que le impulsaron sus ideas democráticas» (sin firma, 1933: 1).

Parco es también el otro artículo sin nombre de autor, el firmado por M. en La Veu de Catalunya, aunque se explaya algo más sobre las cualidades poéticas de la obra de la autora, lamentando su decadencia o el poco conocimiento por parte de las jóvenes generaciones.

En cuanto al artículo ya mencionado de Araujo Costa, contiene una caracterización de la autora (su elegancia, su encanto), a la que sigue un comentario muy elogioso de su obra, destacando la comunión con la naturaleza y el panteísmo, aunque obvia toda la vertiente de su poesía vinculada con el dolor y la muerte. Mientras que R. Blanco Fombona, que califica a Anna de Noailles en su título de «poeta por la gracia de Dios», tras mencionar que conoció en su juventud a su hermano, el príncipe Brancovan, la sitúa en la cúspide de la poesía francesa después de Verlaine, y junto a Moréas ( $\mathrm{y}$, como dice, precisamente una rumana y un griego). Con todo, la parte más interesante de su artículo es la comparación que efectúa entre la poetisa francesa y las de lengua española Ernestina de Champourcin y, sobre todo, la uruguaya Juana de Ibarbourou.

Otros artículos se sitúan a un nivel algo más elevado, y resultan pequeños ensayos literarios, escritos en un lenguaje más académico, incluso lírico, alejado en cualquier caso- de lo que se se entiende por lenguaje periodístico. Es lo que ocurre con el de Miquel Capdevila ${ }^{21}$ en La Veu de Catalunya, el cual, bajo un título anodino, ofrece un estudio altamente literario, con alusiones a otros escritores y citas de poemas de Anna de Noailles. Tras las referencias a las raíces de la autora se describe su obra, en la que, más allá del panteísmo inicial y de la conexión con la naturaleza, aparece la muerte, que en ella se alía con el deseo. Por su parte, Lorenzo Carriba 22 insiste en la recuperación por la autora del sentimiento y la naturaleza en una época de poesía objetiva y descarnada, y presenta una comparación (casi un hermanamiento) con Marcel Proust.

\footnotetext{
${ }^{21}$ Miquel Capdevila (1887-1953) fue un periodista y escritor en lengua catalana, que colaboró en distintos periódicos y revistas, en particular en La Veu de Catalunya, de la que fue jefe de redacción.

${ }^{22}$ No he podido hallar otra información sobre este personaje, más allá de varios artículos publicados en Heraldo de Madrid.
} 
El nombre de Cristóbal de Castro ${ }^{23}$ es el más presente en la bibliografía española de Anna de Noailles (cinco títulos entre 1927 y 1933). En el artículo de La Libertad «Dos mujeres apasionadas», Anna es la poetisa apasionada y Marie Curie la alquimista moderna, ambas de origen extranjero, unidas por el «cuño de Francia» y por el marbete de la excelencia. Pone de relieve Castro la pasión, la sensualidad y el deseo presentes en buena parte de su poesía, hasta L'Honneur de souffrir, que significa «el entierro de Cupido y la resurrección de Psiquis»: la poetisa apasionada cede el paso a la poetisa espiritualizada ${ }^{24}$. Por su parte, Juan Chabás ${ }^{25}$ dio en el texto publicado en $L u z$ un artículo de crítica literaria, evocando la sensualidad de su obra («vida que se desborda en efervescencia de anhelos sensuales»), así como la «herencia inmarchitable» que deja tras su muerte. Y termina comparándola con Safo: «Quedará de su obra y su vida [...] la imagen de una mujer hermosa, petite et claire, como de sí misma dice; pequeña y morena, como de sí misma decía Safo (mikra kai melania)» (Chabás, 1933: 8).

Es también muy elevado el artículo que Díez Canseco escribió para $A B C$, en el que, a partir de su conocimiento de la poesía y del arte, presenta la trayectoria poética de Anna de Noailles y las manifestaciones de la vida, la decadencia física, la muerte... y la fuerza del espíritu (y también del arte) para soslayar todo eso:

Nadie como Madame de Noailles debió comprender en la hora dulce en que la cabeza blanquea, precisamente porque fue mujer y artista suprema, que la vejez tiene una belleza, y que la muerte puede ser vencida con solo haber dejado lo que ella: versos armoniosos (Díez Canseco, 1933: 22).

El artículo de M. ${ }^{a}$ Luz Morales trae a colación en primer lugar algunas afirmaciones irónicas de Ortega y Gasset en su controvertido ensayo sobre Anna de Noailles $^{26}$, como la de que era «la más poética de las condesas y la más condesa de las poetisas» o «la hilandera mayor del lirismo francés». Retomando para su título este calificativo, comenta que «la lírica rueca de Anna de Noailles no ha cesado un instante, en los 32 años que van de siglo, de devanar en sutil poesía el ve-

${ }^{23}$ Cristóbal de Castro (1874-1953) fue redactor o colaborador de numerosos periódicos (La Época, La Correspondencia de España, El Liberal, Heraldo de Madrid, La Libertad), escritor, traductor y autor de varias obras de tipo social (véase Cruz Casado, s. a.).

${ }^{24}$ De hecho, el autor retoma, resumiéndolas, ideas que había expresado varios años antes en el artículo titulado precisamente «La condesa de Noailles o de Cupido a Psiquis» (Nuevo Mundo, XXXIV, n. ${ }^{\circ} 1765$, de 18/11/1927, p. 1).

${ }^{25}$ Juan Chabás (1900-1954) fue un destacado intelectual, miembro de la generación del 27, poeta, novelista y ensayista, así como traductor. Publicó numerosos artículos en Revista de Occidente, La Libertad, Diario de Barcelona, Luz y otros medios.

${ }^{26}$ Se refiere al largo artículo de Ortega «La poesía de Ana de Noailles», publicado en el n. ${ }^{\circ} 1$ de Revista de Occidente (1923, pp. 29-41). No deja de llamar la atención que el ensayista eligiera para su primera contribución en su revista un estudio sobre Noailles, a quien había dedicado muchos años atrás una reseña de su reciente Le Visage émerveillé (en El Imparcial de 25/07/1904, p. 5). El texto ha hecho correr bastante tinta, la primera ya al poco tiempo de su aparición, no tanto por lo que dice de Anna de Noailles, sino por algunas aseveraciones sobre -por decirlo brevemente- la mujer y la poesía. 
llón de paisaje y sentimiento, dolor y belleza, amor y muerte». Y, sin olvidar a Ortega, aborda la cuestión de la lírica femenina, abundando en la idea de que la mujer poeta rehúye la expresión de lo íntimo: «El alma de la mujer es recóndita, hermética. [...] Su sensibilidad, aguzada hasta lo enfermizo, se repliega sobre sí y de su misterio hace su defensa». Aunque Anna de Noailles sería una excepción: «Nos queda el eco de su voz y, en él, ese algo, raro y sutil, que es un exquisito desnudo del alma femenina» (Morales, 1933: 5).

Por último, cabe incluir aquí dos poemas publicados por José María Pemán ${ }^{27}$ en $A B C$, que se presentan como homenaje a Anna de Noailles. En un recuadro insertado en el ángulo inferior derecho de la página, ocupada totalmente por el retrato que de la condesa había hecho Philip de László, dio su versión de los mismos precedida de la siguiente nota: «No se pueden llamar traducciones estas dos poesías que siguen. Tejidas sobre pensamientos de la ilustre poetisa, recién muerta, creo que conservan mejor que las traducciones el reflejo de su espíritu atormentado» (Pemán, 1933: 13). Un poema se titula «Senda triste» y el otro, sin título, empieza por «Escribo porque todos...». No he hallado el original o el modelo del primero, mientras que el segundo está relacionado con el que comienza «J'écris pour que le jour...» del libro L'Ombre des jours.

En cuanto a los artículos aparecidos en revistas, son obra de los siguientes autores: A. R. V. (siglas que corresponden a Aubain Rieu-Vernet) en Cultura Integral y Femenina, Francisco Calvo ${ }^{28}$ en Contemporánea, Cristóbal de Castro en Nuevo Mundo, Agustín de Figueroa ${ }^{29}$ en Blanco y Negro, Charles Malato en La Revista Blanca, Athos Novellis (seudónimo de Giuseppe Torre Caprara) en Mirador, Matilde Ras en Blanco y Negro y Félix $\operatorname{Ros}^{30}$ en Cruz y Raya.

La revista Cultura Integral y Femenina se interesaba más por aspectos relativos a la higiene, la salud, la naturaleza, por una parte, y a asuntos generales de orden histórico, artístico, económico y político, y en menor medida a asuntos literarios. Aun así, su director, Aubain Rieu-Vernet, publicó bajo las siglas A. R. V. un artículo sobre Anna de Noailles, en el que, tras evocar su fallecimiento, va desgranando un encendido elogio de sus méritos poéticos, con numerosas alusiones a sus obras y varias citas de sus poemas:

Para Anna de Noailles, todo era música. Su sensibilidad, siempre hiperestesiada, tañía estrofas plásticas y evocadoras,

\footnotetext{
27 José María Pemán (1897-1981), escritor y político conservador y monárquico, fue autor de numerosos relatos, poemas y ensayos, al tiempo que colaboraba en la prensa. Ocupó varios cargos políticos antes y después de la guerra civil, y fue el principal intelectual del régimen de Franco.

${ }^{28}$ Francisco Calvo Burillo (1881-1936), dominico, aparte de ejercer su labor pastoral colaboró en la revista valenciana Contemporánea, vinculada con la Orden de Predicadores (véase Sin autor, s. a.).

${ }^{29}$ Agustín de Figueroa (1903-1988), marqués de Santo Floro, fue hijo del conde de Romanones; su posición le permitió conocer a numerosas personalidades de su época, entre ellas la condesa de Noailles. Publicó algunas obras literarias y colaboró en distintos periódicos y revistas (véase Quintana, s. a.).

${ }^{30}$ Félix Ros (1912-1974), escritor y periodista, se dedicó a la docencia, la edición y la traducción. Creó algunas revistas de escasa duración y colaboró en otras y en periódicos, como La Vanguardia, Luz, Diario de Madrid o Cruz y Raya (véase Mengual, 2015).
} 
cantando los sufrimientos y las glorias, los gritos de la naturaleza y las angustias sociales. Música de las pasiones y de las ideas; de los sentidos y de los entusiasmos; de los colores y de las formas; de la vida esplendorosa, y hasta de la muerte destructora, a la que parece esperar como una liberación (A.R.V., 1933: 23).

Por su parte, Agustín de Figueroa inicia su artículo en Blanco y Negro con sus recuerdos personales de la condesa de Noailles, a la que había conocido en París en 1931, sobre el fondo del retrato de la poetisa por László, que ocupa toda la página. Confiesa que se sintió decepcionado por su modo de vestir («una toilette audaz, con reminiscencias de otra época»), pues la imaginaba «más alta, más esbelta, casi ingrávida [...] tendida, suelta la cabellera - de esta guisa me habían dicho que solía recibir en el lecho, lo cual justificaba mi visión horizontal- [...] con la actitud de una estatua simbólica, casi con una lira en la mano» (de Figueroa, 1933: 108). Pero la decepción se disipa ante el encanto de la poetisa, a la que define de modo entusiasta:

Ma drogue, c'est mon cerveau. Esta frase suya la define. Subjetiva, ardiente, rebelde, vivió abrasada por un incendio que en sí misma tenía la propia hoguera: Ana de Noailles era de esos seres que no necesitan estímulo ajeno para vivir alucinados por un delirio sobrehumano, por su amor inmenso del amor y de la vida. Drogada se sintió siempre por un magnífico exceso de emotividad (de Figueroa, 1933: 108).

El artículo de Cristóbal de Castro en Nuevo Mundo entronca con otro suyo, aparecido unos días antes en el Heraldo de Madrid, y ambos remiten al ya citado de 1927, publicado en la misma revista. Alude en el de ahora a dos momentos en la obra de Anna de Noailles: el de los primeros libros, teñido de erotismo y de panteísmo, reino de Pan y de Cupido; y el de la crisis espiritualista de L'Honneur de souffrir, la contrición ascética que se opone al anterior frenesí sensual. Cita extensamente una parte del artículo que Maurice Martin du Gard había publicado en Les Nouvelles Littéraires el 7 de mayo de 1927 con motivo de la aparición del mencionado poemario, en el que imagina - con bastante sorna- la defensa de una tesis en la Sorbona, allá por el año 2000, sobre La Comtesse de Noailles et le sentiment tragique de la vie, haciendo un guiño al interés por Unamuno en Francia.

El de Félix Ros en Cruz y Raya «Paso de Valéry y traspaso de la condesa» presenta dos partes: la titulada «Seminario de poesía pura» que contiene, a partir de una entrevista con Paul Valéry en ocasión de una visita a Barcelona, una reflexión sobre la poesía pura, y la denominada «Llama y ceniza de poesía», que con la excusa de la muerte de Anna de Noailles - que no se menciona, al otro extremo del «traspaso» del título, hasta la penúltima línea del texto- transcurre por los complejos vericuetos del amor, la pasión, la mentira y... la poesía. Todo ello, además, aderezado de recuerdos personales y de comentarios particulares, como los reflejados en el último párrafo (las cursivas son del autor):

Se ha hablado excesivamente estos días del espíritu de

Francia que supo continuar la condesa de Noailles. Pero el 
espíritu de Francia no es, como quieren muchos, un cualquier fuego sagrado que sea preciso encender porque se apaga en muertes y vicisitudes. Que es el especial, el antonomásico fuego de vestal, inextinguible si móvil, e impersonal si para todos. No es el espíritu de Les éblouissements esporádicos de la condesa, quien quizá llegó mejor a la entraña de su patria por nación y por amor en los libros últimos, más calmos y más hondos, de su labor. Contemporiza, se mueve, decora. Ella despreocupa la cámara de Périnal, subvencionando a Cocteau, cinéfilo ${ }^{31}$. Se le concede la Legión de Honor. Y recuerdo precisamente un noticiario cinematográfico con la ceremonia; estaba muy envejecida; era eso de una señora muy señora que se ve que ha sido guapa de joven. Quizá fuera la pérdida de su juventud la que artísticamente le hiciera mayor bien. Aparte, en este sentido, del que le haya hecho la muerte; por la paradoja de que el que vive estorbe y se le agradezca la desaparición (Ros, 1933: 136).

Las creencias -religiosas y políticas- parecen haber influido en el tratamiento dado a la figura de Anna de Noailles en algunos artículos. Por ejemplo, en Contemporánea el dominico Francisco Calvo Burillo escribe un largo artículo en el que analiza desde una óptica cristiana su poesía, achacándole su paganismo y su olvido de Dios:

Dígalo, si no, la dulce y triste cantora del Cour innombrable, que entró de lleno por los alcázares de la risueña poesía, que abría todos los poros de su espíritu en recepción de belleza, que aspiró con ilimitada ansia toda la gama del colorido, queriendo encerrar en su alma todas las trovas primaverales. Media vida soñó con la lobreguez de la muerte, porque amando con demasía la vida de los sentidos, olvidó la otra, que es precisamente la que tiene la clave de la muerte. [...] $\mathrm{Y}$ el alma sin idealismo, ¿qué papel juega en este mundo? Hasta la muerte es vida, afirma el P. Lacordaire, si en ella acertamos a sacar los hilos que están sin romper. Es decir, que faltando el recurso de un ideal amado y porfiado, queda acosado en un reducto el poeta, dejando tronchadas no pocas alas en la querella de su espíritu. Este fue el caso de Ana de Noailles (Calvo Burillo, 1933: 34-35).

Ocurre algo similar, aunque desde una óptica muy alejada, con Charles Malato y Giuseppe Torre Caprara. Del primero, anarquista, no podía esperarse un encendido elogio, aunque, como dice, «a pesar de su título de condesa y de su insignia de la Legión de Honor -juguetes de la feria de las vanidades que nada añaden a sus méritos- es justo reconocer que se ha apagado una hermosa estrella del

\footnotetext{
${ }^{31}$ Confunde aquí F. Ros a la condesa de Noailles con la vizcondesa del mismo nombre, esposa de un sobrino de su marido, que junto con su esposo corrieron con los gastos de varios filmes surrealistas, entre ellos Le Sang d'un poète de Cocteau (1930), con Georges Périnal como director de fotografía.
} 
lirismo». Su texto es, en realidad, uno de los apartados de la crónica que escribe desde París para La Revista Blanca, de signo libertario. De ahí la comparación que establece con la anarquista francesa Louise Michel:

Sin ser la heroína apasionada de un ideal libertario, como lo fue Luisa Michel, poeta a su vez, al mismo tiempo que luchadora, cuya vida fue solo sacrificio, lucha y miseria, Ana de Noailles, célebre ya a los veinte años y viviendo en un mundo brillante y unida en matrimonio a un heredero de la aristocracia histórica, merece, a pesar de todo, mejor que honores oficiales de los que no se vio privada, el homenaje de admiración de los hombres de letras y la simpatía del público (Malato, 1933: 86).

Por su parte, el antifascista italiano Torre Caprara, que firma Athos Nove1lis, junto a sus alabanzas a la genialidad femenina y a la obra de Anna de Noailles, que considera una de los mayores poetas europeos, al lado de Musset y Leopardi, dedica un tercio de su artículo al compromiso social y político, ejemplificado con su intervención en el juicio contra los implicados en el denominado «complot de Prats de Molló» ${ }^{32}$ :

És clar que l'activitat de la comtessa de Noailles ha sortit del camp poètic, però el sentiment general ha estat més per la poetessa que no pas per la dona política. La política que apassionava la poetessa no era la de les intrigues que s'ordeixen pels salons $[\ldots]$, entenia per política una cosa més pura i elevada. Voltà de simpatia els catalans exiliats a París en temps de la dictadura, es relacionà amb molts d'ells, i quan tingué lloc el procés contra Macià i els seus companys, l'il·lustre poetessa, no podent anar a declarar davant del tribunal, perqué una bronquitis li ho impedia, trameté una significativa carta (Novellis, 1933: 6).

El último texto contiene unos «apuntes grafológicos»: muy alejados parecen de un acercamiento «literario» a la figura de Anna de Noailles, pero viniendo de quien vienen, de una escritora y traductora como Matilde Ras, no podían estar exentos de un toque literario, si no poético. Tras una presentación del personaje, de lo paradójico de su muerte a las puertas del 1..$^{\circ}$ de mayo, eclosión de la primavera y del renacer, el análisis de los distintos rasgos de su escritura la llevan a enumerar otros tantos de su carácter, que encuentran confirmación en la realidad de su vida y su obra: alma vibrante, emotividad, espontaneidad, asimilación intelectual, imaginación creadora, expresión fácil, memoria visual, sentimiento del colorido...

Este recorrido por las páginas de periódicos y revistas ha permitido calibrar el grado de difusión en España de la persona y la obra de Anna de Noailles, que dependía -cierto es- del interés de directores o jefes de redacción, aunque también de colaboradores de las distintas publicaciones. Al haber focalizado la

\footnotetext{
${ }^{32}$ Este hecho la convirtió en una «amiga de Cataluña», y fue recordado por la prensa catalana en distintas ocasiones, antes y después de su muerte.
} 
atención en los artículos publicados con motivo del fallecimiento de la autora, la inmediatez de la noticia, unida al interés mediático del personaje, hizo que se diera una concentración de artículos en un breve espacio temporal; con todo, la concentración de referencias no conlleva un vacío en un largo periodo que se extiende desde los primeros años del siglo, cuando ya habían aparecido sus primeras obras, hasta más acá de la fatídica primavera de 1933, y que llega hasta nuestros días.

\section{REFERENCIAS BIBLIOGRÁFICAS}

Allard, Marie-Lise (2013): Anna de Noailles: entre prose et poésie. París, l'Harmattan.

Álvarez Chillida, Gonzalo (s. a.): «José María Pemán y Pemartín», in Real Academia de la Historia, Diccionario Biográfico Electrónico. URL: http://dbe.rah.es/biografias/4830/jose-maria-peman-y-pemartin.

BArbeito, María (1962): La condesa de Noailles. Madrid, s. i. (Imp. Juan Bravo 3).

Benjamin, René (1928): Au soleil de la Poésie. Sous l'œil en fleur de Madame de Noailles. París, Librairie des Champs-Élysées.

BiBlioteCA NACIONAL DE EsPAÑA (s. a.): «Manuel Bueno Bengoechea», in Escritores en la BNE. URL: http://escritores.bne.es/web/authors/manuel-bueno-bengoecheapau-1974-barcelona-1936.

BLUM, Léon (1906): En lisant. Réflexions critiques. París, P. Ollendorff.

BROCHE, François (1989): Anna de Noailles. Un mystère en pleine lumière. París, Robert Laffont.

ChABÁs, Consuelo (s. a.): «Juan Ambrosio Chabás Martí», in Real Academia de la Historia, Diccionario Biográfico Electrónico. URL: http://dbe.rah.es/biografias/12022/juan-ambrosio-chabas-marti.

Cruz CASAdo, Antonio (s. a.): «Cristóbal de Castro Gutiérrez», in Real Academia de la Historia, Diccionario Biográfico Electrónico. URL: http://dbe.rah.es/biografias/11626/cristobal-de-castro-gutierrez.

CuencA Toribio, José Manuel (s. a.): «Luis Araujo Costa», in Real Academia de la Historia, Diccionario Biográfico Electrónico. URL: http://dbe.rah.es/biografias/7646/luis-araujo-costa.

Du Bos, Charles (1922): Approximations. Première série. París, Plon.

FERnÁNDEZ URTASUn, Rosa (s. a.): «Ernestina Michels de Champourcin», in Real Academia de la Historia, Diccionario Biográfico Electrónico. URL: http://dbe.rah.es/biografias/12067/ernestina-de-michels-de-champourcin-ymoran-de-loredo.

LA Rochefoucauld, Edmée de (1956): Anna de Noailles. París, Éditions Universitaires.

LAFARGA, Francisco (2020): «Traducciones españolas de la obra de Anna de Noailles». Transfer, 15, 351-370. URL: http://revistes.ub.edu/index.php/transfer/article/view/30207.

LARNAC, Jean (1931): Comtesse de Noailles. Sa vie, son ouvre. París, Éditions du Sagittaire. 
MARCo LÓPEZ, Aurora (s. a.): «María Luz Morales», in Real Academia de la Historia, Diccionario Biográfico Electrónico. URL: http://dbe.rah.es/biografias/13226/maria-luz-morales-y-de-godoy.

MARTINEZ, Frédéric (2018): Anna de Noailles. París, Gallimard.

MARTíNEZ, María (s. a.): «Matilde Ras», in Mujeres literatas. URL: https://mujeresliteratas.wordpress.com/2017/04/02/matilde-ras-1881-1969.

MARtínez PATón, Víctor (s. a.): «Ceferino Rodríguez Alonso de Avecilla», in Real Academia de la Historia, Diccionario Biográfico Electrónico. URL: http://dbe.rah.es/biografias/4686/ceferino-rodriguez-alonso-de-avecilla.

Masson, Georges-Armand (1922): La Comtesse de Noailles. Son æeuvre. París, Éd. du Carnet Critique.

MAURRAS, Charles (1905): L'Avenir de l'intelligence. París, A. Fontemoing.

Mengual, Josep (2015): «Semblanza de Félix Ros Cebrián (1912-1974)», in Portal Editores y Editoriales Iberoamericanos (siglos XIX-XXI), Biblioteca Virtual Miguel de Cervantes. URL: http://www.cervantesvirtual.com/obra/felix-ros-cebrianbarcelona-1912-estambul-1974-semblanza.

Mignot-OgLiastri, Claude (1986): Anna de Noailles, une amie de la princesse Edmond de Polignac. París, Méridiens-Klincksieck.

NoAILlES, Anna de (2013): Euvre poétique complète. Edición de Thanh-Vân Ton-That. París, Éd. du Sandre, 3 vols.

ORTEGA Y GASSET, José (1923): «La poesía de Ana de Noailles». Revista de Occidente, 1, 29-41; también en Obras completas. Madrid, Alianza-Revista de Occidente, 1983, IV, 429-435.

PERRY, Catherine (2003): Persephone Unbound. Dionysian Aesthetics in the Works of Anna de Noailles. Lewisburg (PA), Bucknell University Press.

PERRY, Catherine (2009): Anna de Noailles. URL: http://www.annadenoailles.org.

PIQUER DESVAUX. Alicia (1996): «Narcisismo, alteridad y vitalismo en la poesía de Anna de Noailles», in Marta Segarra \& Àngels Carabí (eds.), Amor e identidad. Barcelona, PPU, 77-86. URL: http://diposit.ub.edu/dspace/handle/2445/34250.

Pizarroso, Alejandro (2010): «El periodismo en el primer tercio del siglo XX». Arbor, 186, 45-54. URL: http://arbor.revistas.csic.es/index.php/arbor/article/view/1189/1194.

PujAnte Segura, Carmen (2014): De la novela corta y la «nouvelle» (1900-1950). Estudio comparativo entre escritoras. Madrid, Síntesis.

QuintanA, Covadonga de (s. a.): «Agustín de Figueroa y Alonso-Martínez», in Real Academia de la Historia, Diccionario Biográfico Electrónico. URL: http://dbe.rah.es/biografias/92671/agustin-figueroa-y-alonso-martinez.

REMENTERÍA, Santiago (2001): «Zuloaga, Noailles y Einstein: encuentros y alusiones». Bidebarrieta, 9, 183-197. URL: https://www.ehu.eus/ojs/index.php/Bidebarrieta/article/view/18427/16173.

RuizA, Miguel, Tomás FernándeZ y Elena TAMARo (2004): «Biografía de Rufino Blanco Fombona», in Biografías y Vidas. La enciclopedia biográfica en línea. URL: https://www.biografiasyvidas.com/biografia/b/blanco_fombona.htm. 
SeOANe, María Cruz (1996): Historia del periodismo en España. Madrid, Alianza, vol. 3 (El siglo $X X)$.

SIN AUTOR (s. a.): «Charles Malato», in Sobre la anarquía y otros temas. URL: https://sobrelaanarquiayotrostemasvidayobradepensadoresy.wordpress.com/2018/ 04/17/charles-malato-vida-y-obra.

SIN AUTOR (s. a.): «Beato Francisco Calvo Burillo», in Santopedia. URL: https://www.santopedia.com/santos/beato-francisco-calvo-burillo.

Singla, Carles (2006): Mirador (1929-1937). Barcelona, Institut d'Estudis Catalans.

TORRENT, Joan y Rafael TASIS (1966): Història de la premsa catalana. Barcelona, Bruguera, 2 vols.

VERONA, Roxana M. (2011): Parcours francophones: Anna de Noailles et sa famille culturelle. París, H. Champion.

\section{APÉNDICE. RELACIÓN DE ARTÍCULOS SOBRE ANNA DE NOAILLES}

A. R. V. [Aubain Rieu-Vernet]: «Anna de Noailles». Cultura Integral y Femenina, 6 (15/06/1933), 23.

Araujo CostA, Luis: «La condesa Mathieu de Noailles». La Época (03/05/1933), 1.

Avecilla, Ceferino R.[odríguez Alonso]: «El verso ignorado de la condesa de Noailles». La Libertad (20/05/1933), 3.

BLANCO FOMBONA, Rufino: «Ana de Brancovan, condesa de Noailles, poeta por la gracia de Dios». El Sol (09/05/1933), $1^{33}$.

BuENO, Manuel: «La musa aristocrática». ABC (28/05/1933), 23-24.

CAlvo Burillo, Francisco: «La condesa de Noailles. Impresiones sueltas». Contemporánea, $\mathrm{I}, \mathrm{n} .{ }^{\circ} 5$ (mayo de 1933), 28-35.

CAPDEVILA, Miquel: «La comtessa de Noailles». La Veu de Catalunya (05/05/1933), 6.

CARRIBA, Lorenzo: «Luto en las letras francesas. En memoria de la difunta condesa de Noailles». Heraldo de Madrid (04/05/1933), 13.

CASTRO, Cristóbal de: «Anna de Noailles. La poetisa del amor». Nuevo Mundo, XL, n. ${ }^{\circ}$ 2045 (19/05/1933), s. p.

CASTRO, Cristóbal de: «Dos mujeres ejemplares». La Libertad (10/05/1933), 1.

CoCTEAU, Jean: «...Hecha para estar muerta. De Jean Cocteau a Madama de Noailles». Heraldo de Madrid (18/05/1933), 13.

CHABÁS, Juan: «Muere una gran poetisa. Imagen de Ana de Noailles». Luz (04/05/1933), 8.

Champourcin, Ernestina de: «La condesa de Noailles». El Sol (04/05/1933), 2.

DíEz CANSECO, José: «Ana de Noailles». ABC (14/05/1933), 22.

FIgUeROA, Agustín de (marqués de Santo Floro): «El dolor de morir (Ana de Noailles». Blanco y Negro (04/06/1933), 107-108.

\footnotetext{
${ }^{33}$ Se reprodujo como «Ana de Brancovan, gran señora y poeta por la gracia de Dios» en La Vanguardia de Manila, el 23/09/1933, p. 12.
} 
LÓPEZ RoBERTS, Mauricio (marqués de Torrehermosa): «Muerte de la poetisa». $A B C$ (09/05/1933), 3 y 5.

M.: «La comtessa de Noailles». La Veu de Catalunya (04/05/1933), 4.

MALATO, Charles: «La vida y muerte de una poetisa» [en la sección «La vida en París»]. La Revista Blanca, XI, n. ${ }^{\circ} 243$ (julio de 1933), 86.

MORALES, María Luz: «La hilandera lírica». La Vanguardia (14/05/1933), 5.

Novellis, Athos [Giuseppe Torre Caprara]: «Mort d'una poetessa. Anna de Noailles». Mirador, 223 (11/05/1933), 6.

PEMÁn, José María: «Homenaje a Anna de Noailles». ABC (20/08/1933), 13.

RAS, Matilde: «Apuntes grafológicos. La condesa de Noailles». Blanco y Negro (14/05/1933), 121-122.

Ros, Félix: «Llama y ceniza de poesía» [en el artículo «Paso de Valéry y traspaso de la condesa»]. Cruz y Raya, 4 (15/07/1933), 131-136, esp. 134-136.

SIN FIRMA: «La condesa de Noailles ha muerto». La Voz (02/05/1933), 1 (ed. de Madrid). 